\title{
ANÁLISE DO TURISMO AMBIENTAL EM MUNICÍPIOS GOIANOS
}

\author{
ANALYSIS OF ENVIRONMENTAL TOURISM \\ ON THE MUNICIPALITIES OF GOIÁS
}

\author{
ANÁLISIS DEL TURISMO DEL MEDIO AMBIENTE \\ EN LOS MUNICIPIOS DE GOIÁS
}

\author{
Janete Rêgo Silva - Universidade Federal de Goiás - Goiânia - Goiás - Brasil \\ janetegt25@gmail.com \\ Nilson Clementino Ferreira - Universidade Federal de Goiás - Goiânia - Goiás - Brasil \\ ncferreira@uol.com.br
}

\section{Resumo}

0 Estado de Goiás tem grande importância no bioma Cerrado, apresentando $97 \%$ do seu território no domínio do bioma. As proporções de ocupação e conversão do bioma em Goiás indicam a necessidade de uma política ambiental que contemple ações de conservação da biodiversidade e o desenvolvimento sustentável das comunidades, sendo o turismo um dos temas estratégicos. Este artigo tem como objetivo caracterizar os municípios que desenvolvem turismo ambiental em relação às variáveis sociais, econômicas, ambientais e institucionais. A metodologia deste trabalho consistiu em levantamento de dados ambientais e socioeconômicos e, em seguida, tratamento e análise dos mesmos em SIG. A análise desses dados possibilitou a identificação dos municípios que possuem melhor infraestrutura ambiental, social e econômica direcionada para o turismo ambiental.

Palavras-chave: Turismo, biodiversidade, Cerrado.

\section{Abstract}

The state of Goiás has a big importance to Biome Cerrado, with $97 \%$ of his territory on this Biome. The proportion of the occupancy and conversion of biome in Goiás indicate the necessity of an environment policy that behold actions of conservation of the biodiversity and the sustainable of development of the community and the tourism is the strategic themes for this policy. The objective of this paper is to characterize the municipality with environment tourism in relation to social, economic and institutional variable. The method of this paper consisted on survey socioeconomic and environment data, forthwith the treatment and analyses of this data on the GIS. The analyze of this data possibility to identify of the municipality that has better infrastructure of the environment, social and economic for the tourism.

Key words: Tourism, biodiversity, Cerrado.

\section{Resumen}

El estado de Goiás tiene una gran importancia en el bioma Cerrado, con $97 \%$ de su territorio con domínio del bioma. Las proporciones de ocupación y conversión del bioma indican la necesidad de una política ambiental que contemple acciones de conservación de la biodiversidad y el desarrollo sustentable de las comunidades, siendo el turismo un de los temas estratégicos. Este artículo tiene como objetivo caracterizar los municipios que tienen el turismo ambiental en cuenta de las variables sociales, económicos, ambientales e institucionales. La metodologia de este trabajo consistió em levantamientos de datos ambientales y socio-económicos, en seguida tratamiento y análisis de ellos en SIG. El análisis de estos datos posibilitó la identificación de los municípios que poseen mejor infra-estructura ambiental, social y económica direccionada para el turismo.

Palabras clave: Turismo, biodiversidad, Cerrado. 


\section{Introdução}

Com uma área de 204 milhões de hectares, o bioma Cerrado é um dos hotspots ${ }^{1}$ mundiais em biodiversidade (Myers et al., 2000). Além de englobar o Planalto Central Brasileiro, desempenha um papel importante quanto aos recursos hídricos do Brasil, devido à grande quantidade de rios e a alta produtividade dos solos (Christofidis, 2006). Entretanto, apesar da riqueza da biodiversidade e recursos hídricos, aproximadamente 80 milhões de hectares do bioma Cerrado já foram convertidos em agricultura e pastagem (Sano et al., 2008).

Grande parte da ocupação e conversão das paisagens naturais do Cerrado ocorreu nas décadas de 1960, 1970 e 1980, por meio dos planos governamentais de expansão da fronteira agrícola nacional. Esse cenário contribui nos dias atuais para a elaboração de políticas que continuem a promover o desenvolvimento, porém de modo que minimizem os impactos ambientais negativos ao bioma.

O Estado de Goiás possui 97\% do seu território dentro do bioma Cerrado. E assim como a grande parte desse bioma, a porcentagem de áreas, que ainda se encontram com cobertura vegetal natural, é limitada, correspondendo a aproximadamente 34,5\% (Sano et al., 2008). Boa parte desta ocupação se deve às políticas de expansão agropecuária, intensificadas a partir da década de 1970 (Miziara; Ferreira, 2008), quando a precária infraestrutura da região e a distância dos principais mercados consumidores passam a ser compensadas por atrativos econômicos e tecnológicos, como incentivos fiscais, baixo preço de terras e o desenvolvimento de novos insumos e práticas agrícolas (variedades de sementes, adubos e maquinários), adaptados ao clima sazonal e ao relevo plano do Cerrado. O estímulo à ocupação do território (Centro-Oeste e Norte do país), visto à época como estratégico para o governo militar (Ferreira, 2009), foi outro motivo importante para que efetivamente houvesse ocupação da área.

As proporções de ocupação e conversão da cobertura vegetal nativa em Goiás indicam a necessidade de elaboração e aplicação de políticas ambientais que contemplem ações de conservação da biodiversidade e o desenvolvimento sustentável das comunidades que podem ser desenvolvidas a partir do turismo, destacado como uma das possíveis atividades estratégicas.

Uma das alternativas propostas atualmente pelo Ministério do Turismo e do Meio Ambiente é o ecoturismo, ou seja, o turismo baseado 
nos recursos naturais, que envolve a experiência e aprendizado ambiental, com baixo impacto sobre o meio social e induzindo a conservação do meio natural (Fennel, 2002). Neste artigo, usa-se o termo turismo ambiental para definir aquele em que se tem como atrativo primeiro os recursos naturais de uma área, ou seja, um turismo natural.

No Estado de Goiás, apenas 6,9\% do território encontra-se protegido em unidades de conservação definidas pela lei, destas apenas $0,9 \%$ o equivalente a $3.304 \mathrm{~km}^{2}$, são de proteção integral, enquanto $6 \%$, o correspondente a aproximadamente $21.159 \mathrm{~km}^{2}$, destinam-se ao uso sustentável (Ferreira et al., 2007). Segundo a Constituição do Estado de Goiás, deveria haver, no mínimo, 20\% do território destinado às Unidades de Conservação para assegurar a representatividade dos ecossistemas. Desse modo, os dados indicam que o estado goiano está longe do mínimo estabelecido pela Constituição.

Com o objetivo de delimitar as áreas com maior impacto da ação antrópica, no ano de 2004 foi desenvolvido o Projeto de Identificação das Áreas Prioritárias para a Conservação da Biodiversidade no Estado de Goiás (PDIAP). Através desse Projeto, foram identificadas 40 unidades de planejamento hexagonais por todo o território goiano por meio da análise de cada hexágono a partir da combinação de dois fatores: a alta pressão antrópica e a elevada importância biológica (Scaramuza et al., 2008).

A proposta da transformação, por meios legais, das Áreas Prioritárias para a Conservação da Biodiversidade em Unidades de Conservação é de fundamental importância para a melhoria da qualidade social e ambiental no estado goiano, bem como da manutenção dos ecossistemas do Cerrado em Goiás.

Os municípios goianos que apresentam turismo ambiental são aqueles em que os investimentos econômicos e sociais se encontram mais estruturados, assim como apresentam características ambientais (relevo, áreas de cobertura vegetal natural remanescentes (MMA, 2007) e desmatamento) mais favoráveis a esse tipo de atividade.

O presente estudo teve como objetivo avaliar os municípios goianos que possuem a prática do turismo ambiental consolidado e as relações com as suas variáveis sociais, econômicas, ambientais e institucionais, a fim de se obter a caracterização dos mesmos e de se inferir o relacionamento entre todas as variáveis consideradas no estudo e o turismo ambiental. 
Materiais e métodos

Área de estudo

A área que aqui é tomada como corpus de estudo corresponde ao território do Estado de Goiás, em específico 18 municípios e 2 distritos (Figura 1), que configuram uma área de $38.944,37 \mathrm{~km}^{2}$, de um total de 340.086,698 $\mathrm{km}^{2}$ (IBGE, 2008). Estes municípios foram escolhidos através de uma pesquisa no sítio eletrônico da Agência Estadual de Turismo Goiás Turismo (www.goiasbrasil.com.br/agetur), por meio da qual foi possível identificar aqueles que apresentavam a prática do turismo ambiental consolidada. Não foram incluídos os municípios que possuem turismo classificado como agroturismo por entender-se que este pode não estar ligado às práticas de conservação da biodiversidade.

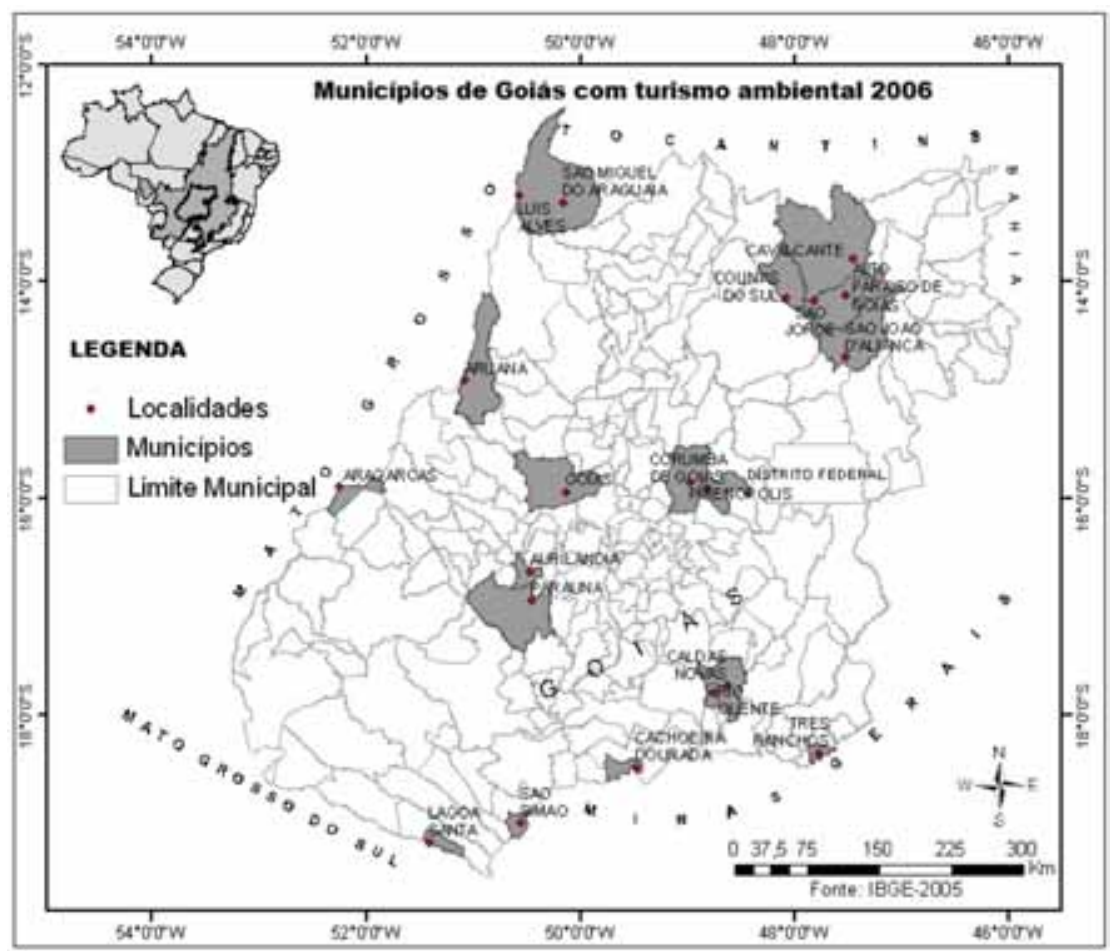

Figura 1 - Mapa de localização dos municípios com turismo ambiental consolidado segundo a Agência Goiana de Turismo, 2006. Fonte: Goiás (2006). 


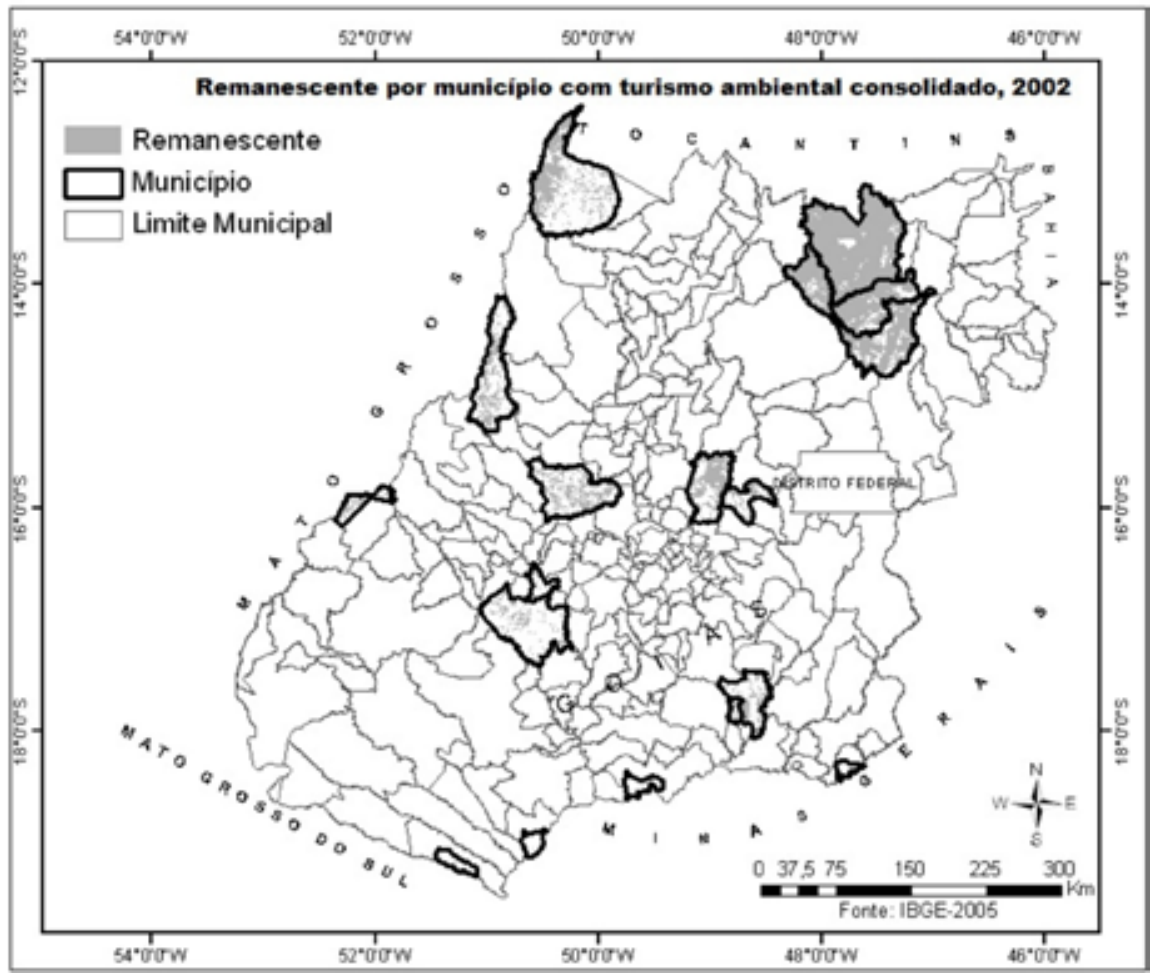

Figura 2 - Mapa de Localização dos municípios com os remanescentes de cerrado encontrados em cada município estudado.

A análise dessas variáveis indicou a relevância do meio natural a esse tipo de turismo. Assim, a proporção da vegetação natural nesses municípios é um fator que resulta relevante, uma vez que a prática do ecoturismo tem como principal atrativo o meio natural. Grande parte desses municípios possui mais de 100.000 hectares de vegetação nativa remanescente (Figura 2). Alguns desses apresentam unidades de conservação dentro de seus limites e estão interceptando algumas Áreas Prioritárias.

\section{Base de Dados}

A elaboração desta pesquisa foi possível devido às bases de dados disponíveis no portal do Sistema Estadual de Estatística e de Informações Geográficas de Goiás (SIEG). Através do SIEG, foram obtidos os arquivos 
vetoriais no formato shapefile indicando limites municipais, rede viária, áreas prioritárias para a conservação da biodiversidade do Estado de Goiás (PDIAP), Unidades de Conservação (UC's) de proteção integral e de uso sustentável, cobertura e uso da terra, além de dados sociais e econômicos, tais como, quantitativo de população, índice de desenvolvimento humano (IDH) e Produto Interno Bruto (PIB), representados em mapas na escala de 1:250.000.

No portal da Goiás Turismo, foram obtidos os dados específicos de localidades com turismo ambiental consolidado, de forma que esses estão representados no mapa como sedes municipais, já que o cálculo das distâncias desses municípios com os demais dados foi realizado a partir das sedes municipais.

Na página eletrônica da Embrapa Monitoramento por Satélite (www.relevobr.cnpm.embrapa.br), foram obtidos os 72 arquivos matriciais com resolução horizontal de 90 metros, a partir do SRTM (Shuttle Radar Topographic Mission), sobre a área que recobre o Estado de Goiás.

Os dados de alerta de desmatamento para o Estado de Goiás foram obtidos a partir da homepage do Laboratório de Processamento de Imagens e Geoprocessamento da Universidade Federal de Goiás (LAPIG/UFG), na qual estão disponíveis os dados relativos aos anos de 2003 a 2007, gerados pelo Sistema Integrado de Alerta de Desmatamento (SIAD-GO).

\section{Métodos}

A análise dos dados, considerando variáveis institucionais, ambientais e socioeconômicas, baseia-se na metodologia adotada por Veiga e Xavier ${ }^{2}$ (2006). A partir dessa metodologia, os dados levantados nesta pesquisa foram tratados com o objetivo de relacionar as diversas variáveis institucionais, ambientais e socioeconômicas, de modo a avaliar como se encontra o turismo ambiental nos municípios indicados.

Foram feitos buffers na proporção de 20 em $20 \mathrm{~km}^{2}$ até $100 \mathrm{~km}^{2}$, tendo com ponto de origem a sede de cada município e com o intuito de extrair as informações relacionadas com as variáveis ambientais, sociais e econômicas, de acordo com a distância do ponto de origem.

Após essa primeira etapa, foi realizada a intersecção espacial dos buffers com as variáveis de remanescentes de vegetação nativa, usos da terra, rede viária, unidades de conservação de proteção integral e de uso 
sustentável e do Produto Interno Bruto (PIB), a partir da qual foi possível identificar, em quilômetros, as áreas que correspondem a cada variável definida, mostrando suas regiões de ocorrência. No uso do SRTM, foi possível extrair os dados de declividade, para, em seguida, se obter o mapeamento do desvio-padrão da declividade, a fim de se avaliar as características do relevo dos municípios estudados.

Um levantamento realizado nas páginas eletrônicas dos municípios goianos que apresentam a prática do turismo ambiental consolidado, aqui tomados como parte do corpus de estudo, ofereceu dados referentes a instituições que se relacionam tanto com o turismo quanto com o meio ambiente.

Com relação à análise comparativa entre as áreas prioritárias e os municípios com turismo ambiental consolidado, foi possível verificar a distância dos mesmos em relação a cada área, bem como analisar quais os municípios que as interceptavam. Esta análise teve como objetivo entender de que maneira esses municípios que já possuem infraestrutura turística podem influenciar na conservação dessas áreas.

\section{Resultados e discussões}

Sabe-se que, em geral, os municípios mais populosos oferecem melhor infraestrutura de serviços, tais como: rede bancária, postos de gasolina, restaurantes, hotéis e outros, para atender a sua população e, muitas vezes, também a população de municípios vizinhos que não possuem a mesma infraestrutura. Tal fator se verifica ainda ao correlacionarmos os dados de população com o mapa de distância das sedes de cada município, que indicam que os municípios mais populosos também possuem melhor infraestrutura em oposição àqueles com índice populacional menor. Esta observação é relevante, uma vez que tais dados interferem diretamente na oferta e na demanda do turismo nestas localidades.

Considerando alguns municípios que estão próximos às áreas mais populosas do Estado de Goiás, conforme Tabela 1, queremos destacar Lagoa Santa, com respectivamente 1.125 habitantes, e São Simão com população total de 13.832 habitantes. Tendo por base tais dados podese inferir que a população de Lagoa Santa se beneficia da infraestrutura que o município de São Simão possui devido à proximidade entre eles. O mesmo ocorre em relação ao município de Caldas Novas, geograficamente 
próximo ao município de Rio Quente. Caldas Novas possui maior índice populacional de todos os municípios indicados que apresentam a prática do turismo ambiental consolidado em oposição ao índice populacional de Rio Quente, que, por sua vez, se beneficia da infraestrutura do município vizinho de Caldas Novas.

Tabela 1 - População dos Municípios com turismo ambiental. IBGE, (2007).

\begin{tabular}{|l|l|c|}
\hline Município & Microrregião & PoPULAÇão 2007 \\
\hline Caldas Novas & Meia Ponte & 62.204 \\
\hline Goiás & Rio Vermelho & 24.472 \\
\hline São Miguel do Araguaia & São Miguel do Araguaia & 22.468 \\
\hline Pirenópolis & Entorno de Brasília & 20.460 \\
\hline Aragarças & Aragarças & 17.156 \\
\hline São Simão & Quirinópolis & 13.832 \\
\hline Paraúna & Vale do Rio dos Bois & 10.926 \\
\hline Cavalcante & Chapada dos Veadeiros & 9.875 \\
\hline Corumbá de Goiás & Entorno de Brasília & 9.190 \\
\hline São João d'Aliança & Chapada dos Veadeiros & 8.177 \\
\hline Cachoeira Dourada & Meia Ponte & 7.567 \\
\hline Alto Paraíso de Goiás & Chapada dos Veadeiros & 6.638 \\
\hline Aruanã & Rio Vermelho & 6.476 \\
\hline Colinas do Sul & Chapada dos Veadeiros & 3.856 \\
\hline Aurilândia & Anicuns & 3.719 \\
\hline Rio Quente & Meia Ponte & 2.959 \\
\hline Três Ranchos & Catalão & 2.862 \\
\hline Lagoa Santa & Quirinópolis & 1.225 \\
\hline
\end{tabular}

O Índice de Desenvolvimento Humano (IDH) é um dado que revela o caráter de desenvolvimento dos municípios agregando renda, educação e longevidade.

A partir dos dados coletados, foi possível averiguar que grande parte dos municípios pesquisados que possuem a prática do turismo ambiental apresentam IDH superior a 0,7. Isso demonstra que esses municípios se encontram em uma boa situação de desenvolvimento no que diz respeito à geração de riquezas econômicas. O desenvolvimento e a sustentabilidade se apresentam como um paradoxo das políticas para a conservação, pois visa manter o crescimento econômico responsável 
garantindo a conservação do meio natural (GOÉS, 2009). Desse modo, os municípios que apresentam a prática do turismo ambiental consolidado possuem maior potencial para o desenvolvimento sustentável, uma vez que a prática do ecoturismo necessita da conservação do meio natural aliada ao desenvolvimento econômico. Contudo, é importante considerar que o IDH não deve ser fator único para se entender a potencialidade de desenvolvimento desses municípios por não incluir o meio natural como variável de análise.

Tabela 2 - IDH por municípios com turismo ambiental consolidado, IBGE, (2000).

\begin{tabular}{|l|l|c|}
\hline Município & Microrregião & IDH 2000 \\
\hline Rio Quente & Meia Ponte & 0,806 \\
\hline Caldas Novas & Meia Ponte & 0,802 \\
\hline Três Ranchos & Catalão & 0,788 \\
\hline Cachoeira Dourada & Meia Ponte & 0,759 \\
\hline São Simão & Quirinópolis & 0,754 \\
\hline Aragarças & Aragarças & 0,748 \\
\hline Paraúna & Vale do Rio dos Bois & 0,742 \\
\hline Alto Paraíso de Goiás & Chapada dos Veadeiros & 0,738 \\
\hline São Miguel do Araguaia & São Miguel do Araguaia & 0,737 \\
\hline Goiás & Rio Vermelho & 0,736 \\
\hline Aurilândia & Anicuns & 0,732 \\
\hline Aruanã & Rio Vermelho & 0,721 \\
\hline São João d'Aliança & Chapada dos veadeiros & 0,718 \\
\hline Corumbá de Goiás & Entorno de Brasília & 0,716 \\
\hline Pirenópolis & Entorno de Brasília & 0,713 \\
\hline Colinas do Sul & Chapada dos Veadeiros & 0,671 \\
\hline Cavalcante & Chapada dos Veadeiros & 0,609 \\
\hline Lagoa Santa & Quirinópolis & $0 *$ \\
\hline
\end{tabular}

* Lagoa Santa não possuía dados de IDH para o ano de 2000.

Alguns dos municípios analisados estão inseridos na região considerada de baixo desenvolvimento, ou seja, que apresentam IDH baixo (parâmetro definido pelo IBGE), bem como taxa de desenvolvimento 
inferior, tais como Colinas do Sul e Cavalcante. Segundo Novaes et al. (2008), a maioria da população pobre necessita muito mais do meio natural para sobreviver, pois seu acesso ao bem-estar é restrito. Desta maneira, é possível inferir que desenvolver uma política conservacionista em Goiás poderá favorecer as populações que se encontram em municípios com baixo índice de desenvolvimento, uma vez que tal política priorizara atividades voltadas para a valoração das terras com remanescentes de Cerrado em oposição às áreas já convertidas.

No Estado de Goiás, os municípios com turismo ambiental consolidado possuem, em sua maioria, infraestrutura de acesso bem organizada, conforme a Figura 5, que ilustra de que maneira as rodovias pavimentadas estão distribuídas por todo o Estado. A rede viária é uma das variáveis de fundamental importância para o desenvolvimento do turismo nessas

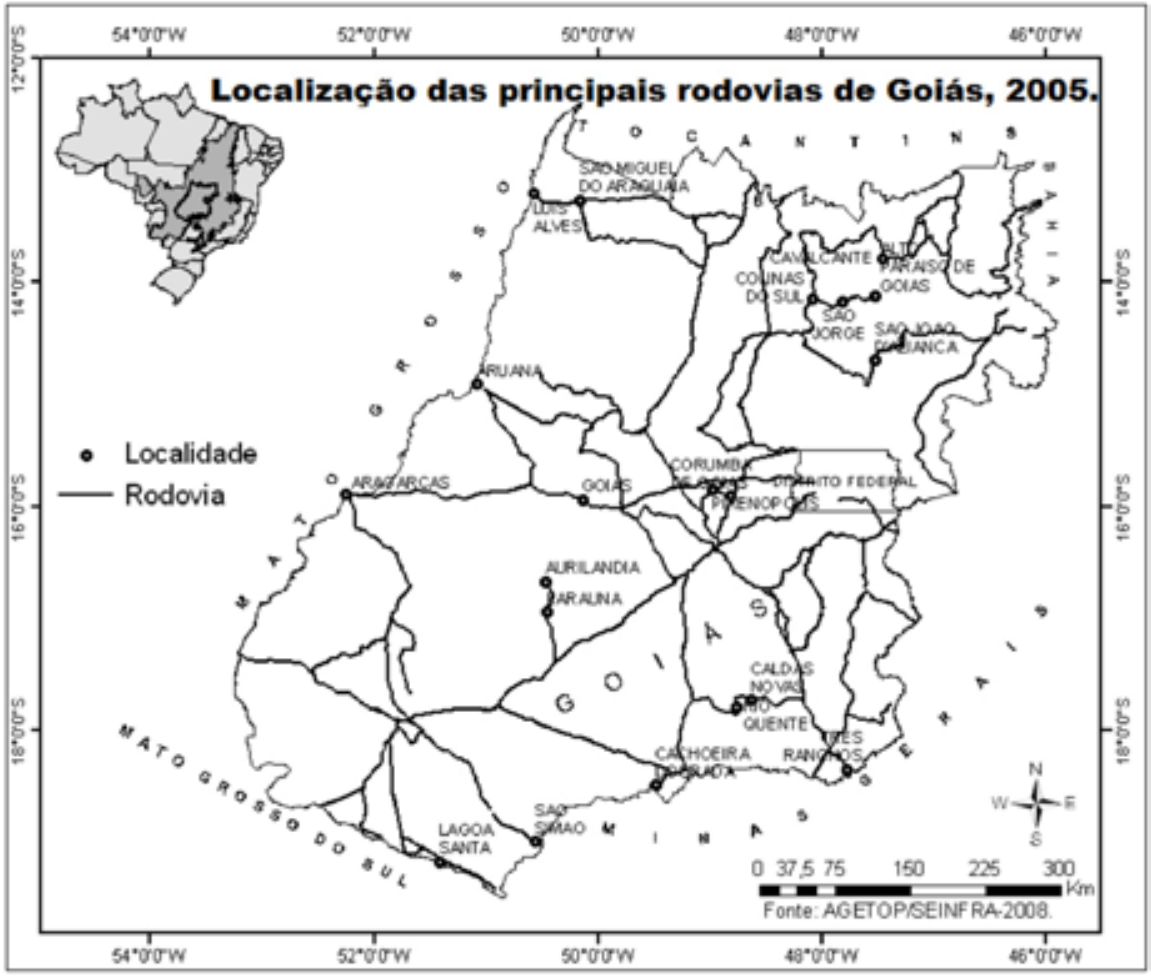

Figura 5 - Mapa de rodovias de acesso aos municípios com turismo ambiental. 
localidades. Assim, quando a rodovia está em bom estado de uso, viabiliza o acesso de visitantes. No estado goiano, o distrito de Luís Alves não possuía rodovia de acesso pavimentada, contudo nas temporadas de férias o distrito recebe muitos turistas, fato este que motivou o recente processo de pavimentação da via que dá acesso ao distrito goiano de Luís Alves.

O Produto Interno Bruto (PIB) desses municípios pode ser observado na Figura 6, na qual se verifica que o município que apresentou maior PIB no ano de 2005 foi São Simão, com R\$ 548.860.029, em oposição ao município de Lagoa Santa, com o menor índice correspondendo a R\$ 6.526.916. A partir das análises dos dados foi possível observar que as relações dos municípios que possuem maior área de remanescentes coincidem com os municípios que possuem um PIB mais baixo.

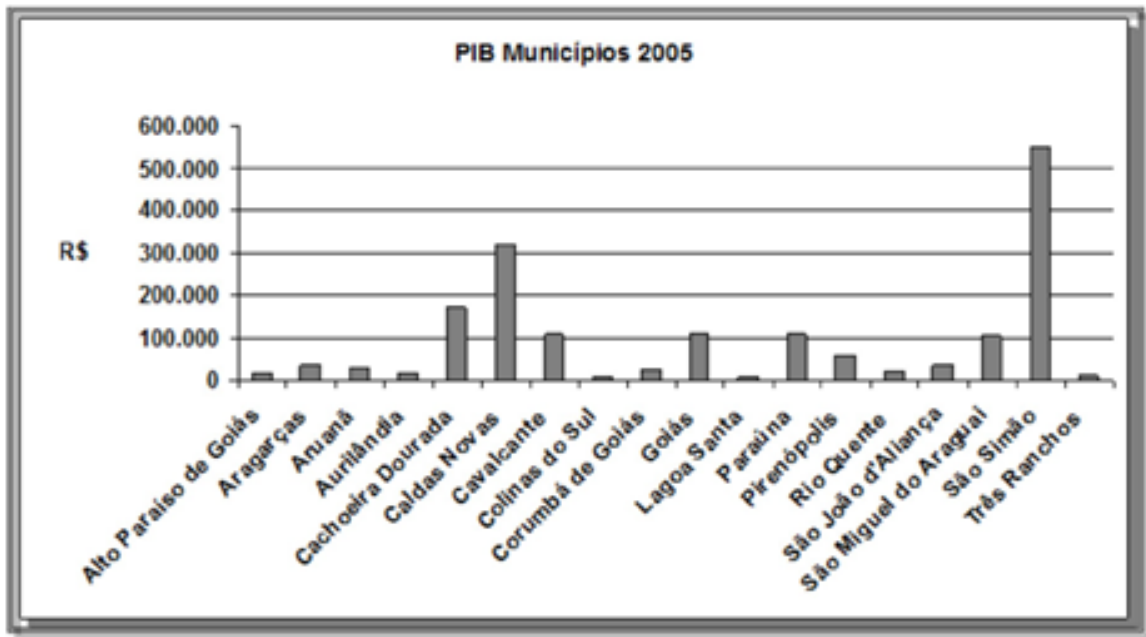

Figura 6 - Produto Interno Bruto para os municípios com turismo ambiental consolidado. Fonte: IPEA (2005).

Considerando a proporção de vegetação nativa remanescente para cada município estudado, é possível identificar que esta variável ao longo dos buffers de 20,40,60, 80 e $100 \mathrm{~km}$ é pouco significativa quanto às mudanças no aumento da vegetação natural. Somente quando se distancia de 20 para $100 \mathrm{~km}$ é que se pode notar uma mudança nesta proporção de vegetação remanescente. Contudo, a variação é inexpressiva (Figura 7). A Tabela 3 apresenta a quantidade de vegetação remanescente para todos 
os municípios pesquisados, a partir da qual podemos apontar Cavalcante como o município com maior área de vegetação remanescente, opondo-se ao município de São Simão com a menor área de vegetação preservada. Como atrativo ao turismo natural, é possível dizer que a relação entre a proporção de remanescente de Cerrado e o turismo é de total relevância, uma vez que as belezas cênicas dessas áreas podem proporcionar essa prática.
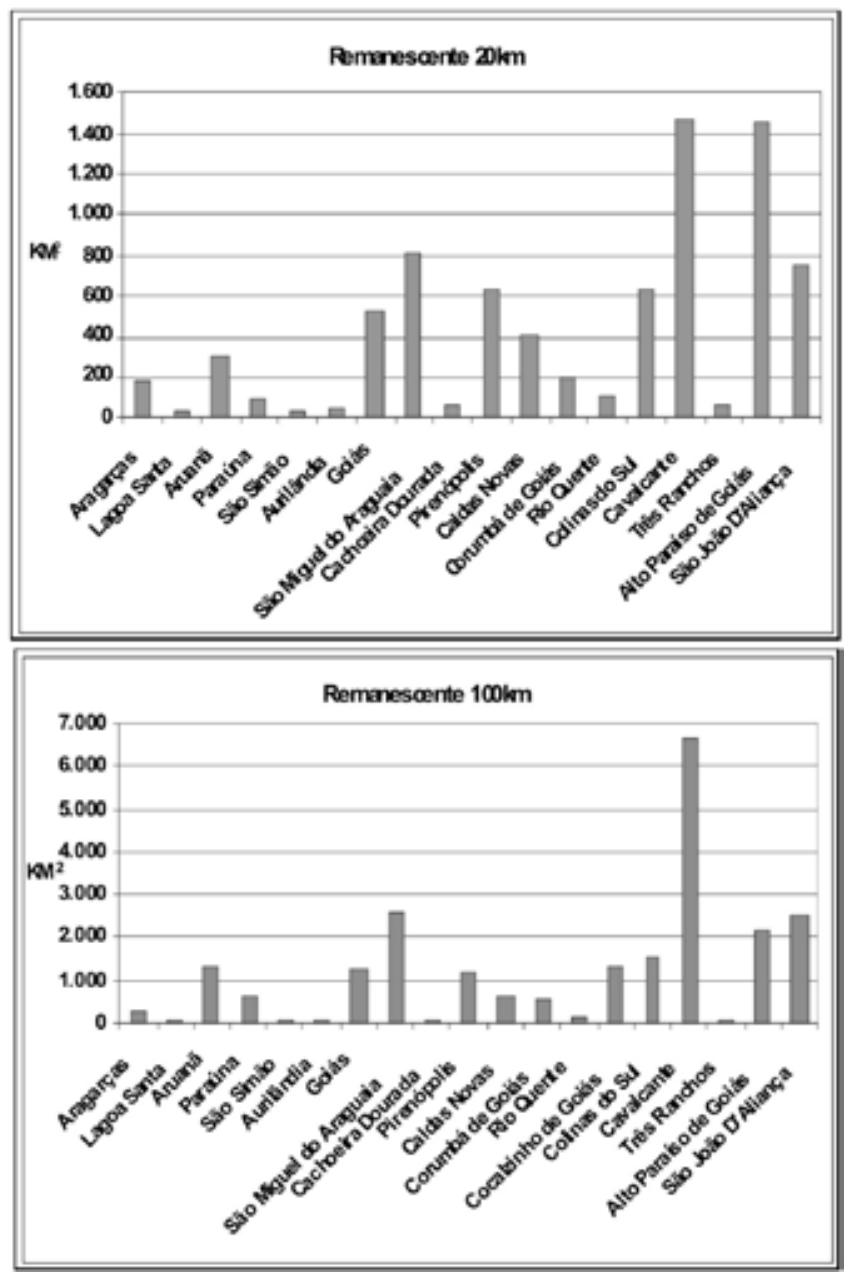

Figura 7 - Gráfico de remanescentes de 20 e 100 km. 
Por meio da análise dos diferentes tipos de usos da terra para cada município foi possível averiguar que, de acordo com o distanciamento da sede do município de 20 em $20 \mathrm{~km}$ até $100 \mathrm{~km}$, os usos se alteram (Figura 8). No buffer de $20 \mathrm{~km}$ a proporção de remanescentes está acima do valor de pastagem e de agricultura; isso indica que próximo aos municípios a cobertura vegetal é mais conservada, visto que as atividades de pecuária e agricultura desenvolvem-se em áreas mais distantes dos centros urbanos. Em contrapartida, quando se aplica o buffer de $40 \mathrm{~km}$, a pastagem apresenta aumento em relação ao quantitativo remanescente. No entanto, quando aplicados os buffers de 60 e de $80 \mathrm{~km}$, os usos não variam consideravelmente; somente quando se aplica um buffer de $100 \mathrm{~km}$ fica perceptível uma mudança mais significativa em relação aos usos da terra, em que é notável uma inversão da quantidade de área de remanescentes de Cerrado para uso agrícola e de pecuária, de acordo com a distância da sede municipal.

Tabela 3 - Área de remanescentes por município, em km².

\begin{tabular}{|l|r|}
\hline Municípios & Área em $\mathbf{~ k m}^{2}$ \\
\hline Alto Paraíso de Goiás & 2.187 .667 \\
\hline Aragarças & $30.467,88$ \\
\hline Aruanã & $132.605,41$ \\
\hline Aurilândia & 43.893 \\
\hline Cachoeira Dourada & 79.256 \\
\hline Caldas Novas & 610.995 \\
\hline Cavalcante & $666.260,51$ \\
\hline Colinas do Sul & $152.034,75$ \\
\hline Corumbá de Goiás & $52.482,61$ \\
\hline Goiás & $125.550,71$ \\
\hline Lagoa Santa & 35.065 \\
\hline Paraúna & 609.276 \\
\hline Pirenópolis & $11.857,092$ \\
\hline Rio Quente & $106.802,3$ \\
\hline São João d'Aliança & $251.520,10$ \\
\hline São Miguel do Araguaia & $257.720,83$ \\
\hline São Simão & $24.969,2$ \\
\hline Três Ranchos & $55.960,5$ \\
\hline
\end{tabular}




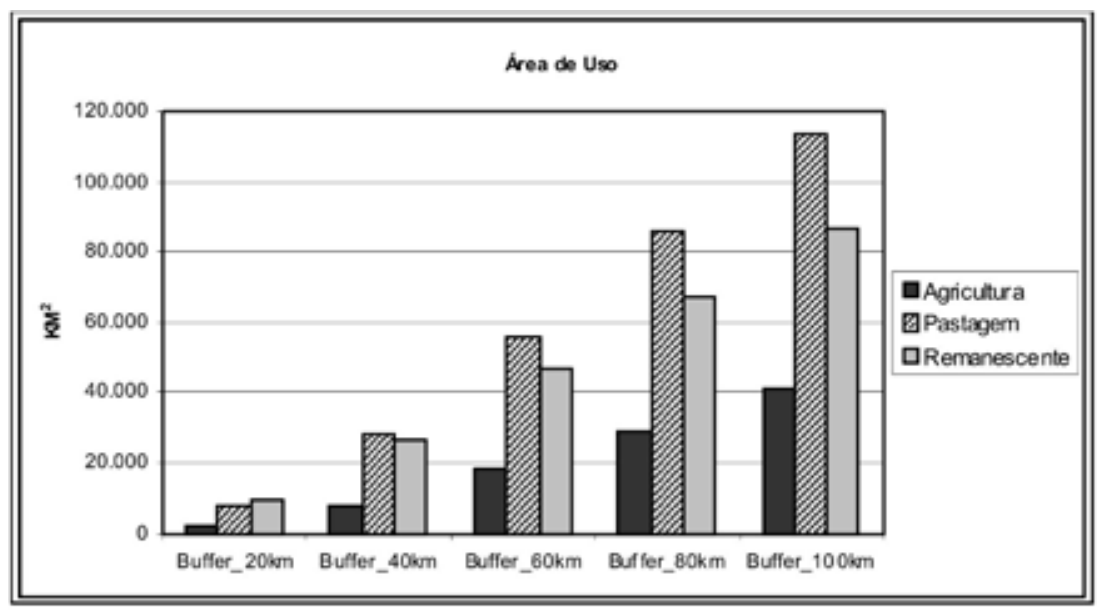

Figura 8 - Gráficos de uso da terra para os municípios de turismo ambiental consolidado em relação aos buffers de 20, 40, 60, 80 e 100 km.

Conforme disposto no Quadro 1, algumas instituições são prioritárias para o desenvolvimento de projetos de sustentabilidade e atividades relacionadas com o turismo ambiental. Contudo, boa parte do território goiano não possui sedes dessas instituições, sobretudo os municípios tomados como objetos de estudo da presente pesquisa. Alguns dos municípios pesquisados possuem Secretaria de Turismo bem como de Meio Ambiente, outros apenas uma das duas secretarias, Turismo ou Meio Ambiente, e o Centro de Atendimento ao Turista (CAT). Apenas o município de São Miguel do Araguaia possui posto de atendimento do Instituto Brasileiro do Meio Ambiente e dos Recursos Naturais Renováveis (IBAMA). Vale ressaltar também que nenhum dos municípios pesquisados possui postos da Secretaria Estadual de Meio Ambiente e Recursos Hídricos (SEMARH), conforme disposto no Quadro 2. Estes dados revelam a urgente necessidade de melhoria institucional no estado goiano. Assim, entende-se que, quanto maior for o número de instituições ligadas ao meio ambiente e ao turismo, maior será a preocupação em manter atividades de conservação do meio natural, garantindo assim o desenvolvimento do turismo ambiental nestes municípios. 
Quadro 1 - Instituições ligadas ao turismo e meio ambiente em Goiás.

\begin{tabular}{|c|c|c|c|c|c|}
\hline \multirow[b]{2}{*}{ Municípios de Goiás } & \multicolumn{5}{|c|}{ Instituições } \\
\hline & $\begin{array}{c}\text { Secretaria de } \\
\text { Turismo }\end{array}$ & $\begin{array}{c}\text { Secretaria do } \\
\text { Meio Ambiente }\end{array}$ & CAT & IBAMA & SEMARH \\
\hline Alto Paraíso de Goiás & Sim & Sim & Sim & Não & Não \\
\hline Aruanã & Sim & Sim & $\operatorname{Sim}$ & Não & Não \\
\hline Aragarças & Sim & Não & Sim & Não & Não \\
\hline Aurilândia & Não & Não & Não & Não & Não \\
\hline Cavalcante & Sim & Não & Sim & Não & Não \\
\hline Cachoeira Dourada & Sim & Sim & Não & Não & Não \\
\hline Caldas Novas & Sim & Sim & Sim & Não & Não \\
\hline Corumbá & $\operatorname{Sim}$ & Sim & $\operatorname{Sim}$ & Não & Não \\
\hline Colinas do Sul & Sim & Não & Sim & Não & Não \\
\hline Cidade de Goiás & $\operatorname{Sim}$ & Sim & $\operatorname{Sim}$ & Não & Não \\
\hline Lagoa Santa & Sim & Não & Sim & Não & Não \\
\hline Luís Alves & $\begin{array}{l}\text { Distrito de } \\
\text { Aruanã }\end{array}$ & $\begin{array}{l}\text { Distrito de } \\
\text { Aruanã }\end{array}$ & Sim & Não & Não \\
\hline Pirenópolis & Sim & Sim & Sim & Não & Não \\
\hline São Jorge & $\begin{array}{c}\text { Distrito de Alto } \\
\text { Paraíso }\end{array}$ & $\begin{array}{l}\text { Distrito de Alto } \\
\text { Paraíso }\end{array}$ & Sim & Não & Não \\
\hline São João d'Aliança & Sim & Sim & Sim & Não & Não \\
\hline São Miguel do Araguaia & Sim & Sim & Não & Sim & Não \\
\hline São Simão & Sim & Sim & Sim & Não & Não \\
\hline Rio Quente & Sim & Sim & Sim & Não & Não \\
\hline Três Ranchos & Sim & Não & Não & Não & Não \\
\hline Paraúna & Sim & Sim & Sim & Não & Não \\
\hline
\end{tabular}

Fonte: Prefeituras, 2009.

A avaliação dos municípios pesquisados levou em consideração também o relevo, uma vez que esta variante contribui para a formação da paisagem, interferindo assim em relação à ocupação bem como ao uso do solo e à vulnerabilidade ambiental. A Figura 9 indica a declividade presente nos territórios pesquisados a partir dos buffers de 20, 40, 60, 80 e $100 \mathrm{~km}$. De acordo com a análise, à medida que se distancia da sede municipal, o desvio padrão da declividade diminui progressivamente, revelando assim que na distância de até $40 \mathrm{~km}$ dos municípios a declividade se apresenta 
bem movimentada, para em seguida reduzir-se. Ou seja, até $40 \mathrm{~km}$ das sedes dos municípios é possível encontrar áreas mais atrativas para as práticas de turismo ambiental, tais como o ecoturismo e o turismo de aventura, dentre outros.

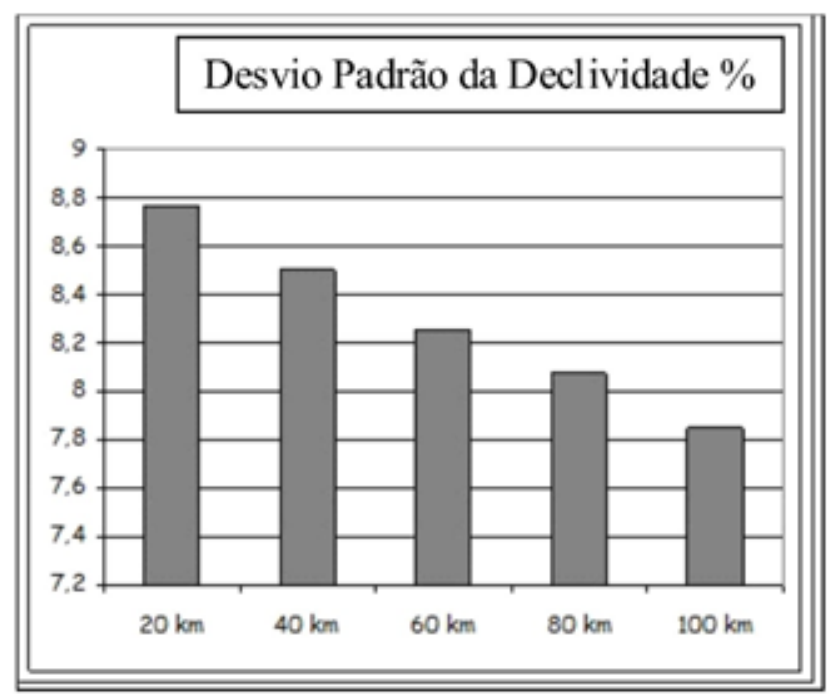

Figura 9 - Gráfico de desvio padrão calculado a partir da declividade.

As áreas prioritárias para a conservação da biodiversidade estão dispostas por todo o Estado de Goiás, e a sua conservação é tomada como prioritária a partir da política ambiental. Tomando como parâmetro a análise da distância dos municípios pesquisados em relação a essas áreas prioritárias de conservação, foi possível averiguar que onze desses municípios interceptam essas unidades e os oito restantes estão a uma distância de até $40 \mathrm{~km}$ das mesmas. Isto indica que algumas áreas prioritárias já estão com turismo ambiental consolidado. Tal fato nos leva a concluir que essas áreas devem ser de fato transformadas em unidades de conservação, garantindo, desta forma, a sustentabilidade do turismo ambiental nesses municípios.

O Cerrado de Goiás possui uma elevada incidência de alertas de desmatamento, contudo, não é possível mensurar se o mesmo ocorre em progressão geométrica (Silva et al., 2009). Desta forma, é possível apenas dizer que o desmatamento é um fator que impacta, de forma negativa, as 
políticas e métodos de conservação, e, portanto, afeta o desenvolvimento do ecoturismo, que possui as áreas naturais como atrativo principal. Logo, Goiás encontra-se em uma região denominada celeiro agrícola mundial, ou seja, área necessária para o cultivo e produção dos alimentos tanto para consumo interno como externo, de forma que suas áreas naturais estão muito convertidas para tal fim.

O Gráfico 10 demonstra as áreas em $\mathrm{km}^{2}$, dentre os municípios pesquisados, que apresentam desmatamento entre os períodos de 2003 a 2007. A partir dessa variante, percebe-se a importância de desenvolver um turismo ambiental planejado e consciente, que auxilie nas políticas de conservação das áreas naturais ainda existentes em Goiás.

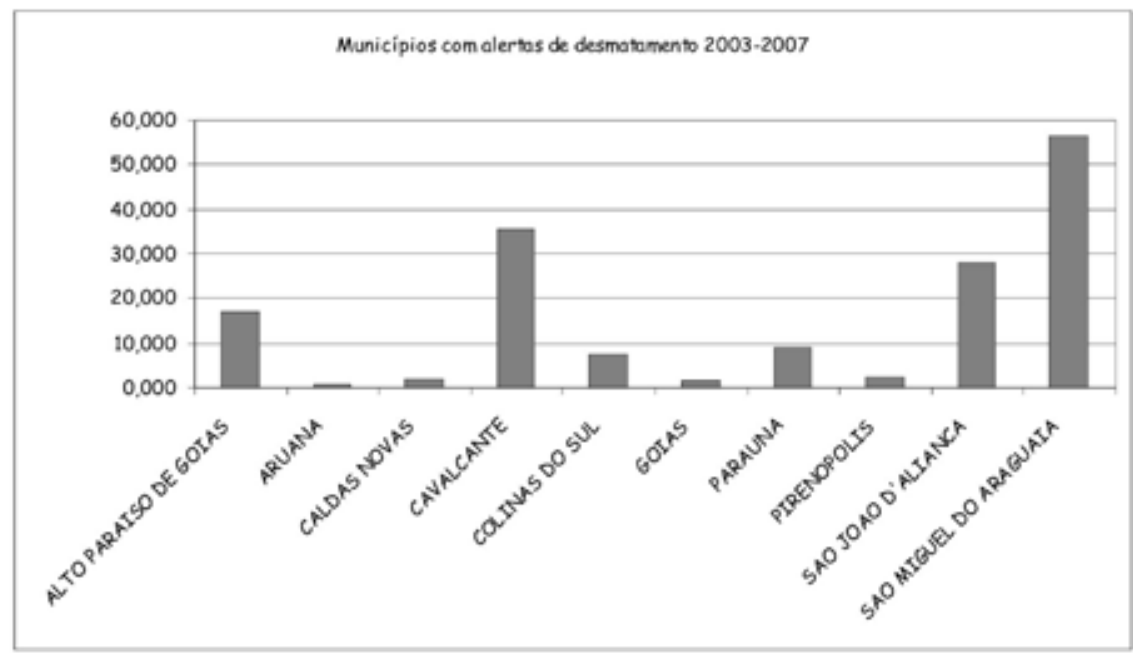

Figura 10 - Gráfico de alertas de desmatamento para os anos de 2003-2007.

Fonte: LAPIG, 2009.

Percebe-se que, em alguns municípios, as áreas de alerta de desmatamento são mais elevadas, tais como, em São Miguel do Araguaia, Cavalcante e São João d'Aliança. O município de Cavalcante apresenta ainda a maior área de remanescentes, contudo é o segundo município com maior área de alertas de desmatamento no período pesquisado. 


\section{Conclusão}

A prática do turismo ambiental em Goiás se mostrou de fundamental importância, pois se apresenta como uma alternativa para o desenvolvimento do Estado e para a melhoria das condições de vida das populações locais. No entanto, as políticas de conservação e de turismo não estão baseadas em métodos científicos que garantam uma legitimidade na metodologia utilizada, com intuito de propor estratégias de uso de locais para o turismo, e que levem em consideração as questões de manejo dessas áreas.

As áreas de conservação no estado goiano, conforme demonstrado, são ínfimas, e partindo desse pressuposto se faz necessária a conservação do que restou do Cerrado, de maneira a favorecer o desenvolvimento sustentável e a conservação do meio natural.

Neste trabalho, pôde-se perceber uma forte relação entre os dados socioeconômicos e os ambientais. Neste contexto, é possível verificar que os maiores índices de IDH estão em áreas com poucos remanescentes de vegetação nativa e, consequentemente, os menores índices estão em locais com expressiva quantidade de remanescentes. Essa relação também é válida no que se refere aos índices de desmatamento, tendo em vista que as regiões do estado goiano que apresentam um IDH alto também revelam um alto índice de desmatamento, logo, com uma baixa incidência de vegetação natural.

Quando se analisam os dados de população e de usos da terra, percebe-se que as áreas mais populosas apresentam maiores índices de antropização em oposição àquelas com menor índice populacional. Dessa maneira, fica evidente a relação entre o meio físico e o socioeconômico, relação esta que deve ser levada em consideração quando se interessa discutir e apontar possibilidades de conservação e de usos da terra.

As discussões apresentadas neste artigo, sobre o diagnóstico da situação econômica, social e ambiental dos municípios que possuem turismo ambiental consolidado no Estado de Goiás, almejam contribuir para propor medidas mais eficientes de conservação ambiental e desenvolvimento sustentável. 


\section{Nota}

1 Hotspots é toda área prioritária para conservação, isto é, de alta biodiversidade e ameaçada no mais alto grau.

2 Essa metodologia consistia basicamente em levantamento e tratamento de dados socioeconômicos, físicos e bióticos.

\section{Referências}

CHRISTOFIDIS, D. Oportunidades de irrigação no Cerrado: recursos hídricos dos cerrados e seu potencial de utilização na irrigação. Revista Item: Irrigação e Tecnologia Moderna, Brasília: ABID, n. 69-70, p. 87-97, 2006.

FENNEL, D. A. Ecoturismo - uma introdução. Tradução de Inês Lohbauer.São Paulo: Contexto, 2002.

FERREIRA, M. E. Modelagem da dinâmica de paisagem do Cerrado. Tese (Doutorado) - Programa de Pós-Graduação em Ciências Ambientais, Universidade Federal de Goiás, Goiânia, 2009.

FERREIRA JUNIOR, L. G.; FERREIRA, N. C.; IGLIORI, D. Sistema de reserva legal extrapropriedade em Goiás: análise de custos e benefícios econômicos e ambientais à escala da paisagem. Boletim Goiano de Geografia, v. 27, p. 11-25, 2007.

GOÉS, K. Metodologia para a análise da vocação turística. Disponível em: mundogeo.com.br. Acesso em: 20 mar. 2009.

KLINK, C. A., MACHADO, R. C. A conservação do Cerrado brasileiro. Megadiversidade, v. 1, n. 1, p. 147-155, jul. 2005.

MMA - MINISTÉRIO DO MEIO AMBIENTE/SBF. Mapeamento da cobertura vegetal do bioma cerrado. Relatório final. Edital Probio 02/2004. Projeto Executivo B.02.02.109. Brasília, junho, 2007.

MIZIARA, F.; FERREIRA, M. E.; FERREIRA, L. G.; RIBEIRO, F. L.; FERREIRA, N. C. Preço da terra e remanescentes do bioma Cerrado: Uma análise integrada para o Estado de Goiás. In: IV Encontro Nacional da Anppas, 2008, Brasília. Anais IV ENANPPAS (CD-Rom). Brasília: CAPES/FAPESP/UnB-CDS, 2008.

MYERS, N.; MITTERMEIER, R. A.; MITTERMEIER, C. G.; FONSECA, G. A. B., KENT, J. Biodiversity Hotspots for Conservation Priorities. Nature, v. 403, p. 853858, 2000.

NOVAES, P. C.; LOBO, F.; FERREIRA, M. E. Pobreza, desenvolvimento e conservação da biodiversidade em Goiás. In: FERREIRA, Laerte Guimarães (Org.). A encruzilhada socioambiental: biodiversidade, economia e sustentabilidade no Cerrado. Goiânia: Ed. UFG, 2008. p. 127-149.

SANO, E.E.; ROSA, R.; BRITO, J.L. S.;FERREIRA, L. G. Mapeamento semidetalhado do uso da terra do bioma Cerrado. Pesquisa Agropecuária Brasileira, v. 43, n. 1, p. 153-156, 2008. 
SCARAMUZA, C. A. M. de; MACHADO, R. B.; RODRIGUES, S. T; RAMOS NETO, M. B; PINAGÉ, E. R.; DINIZ FILHO, J. A. F. Áreas prioritárias para a conservação da biodiversidade. In: FERREIRA, Laerte Guimarães (Org.). A encruzilhada socioambiental: biodiversidade, economia e sustentabilidade no Cerrado. Goiânia: Ed. UFG, p. 13-66, 2008.

SERRANO, Célia; BRUHNS, Heloísa T. (Orgs.). Viagens à natureza: turismo, cultura e ambiente. Campinas, SP: Papirus, 1997.

SILVA, E. B.; FERREIRA, L. G.; ROCHA, G. F.; COUTO, M. S. D. Taxas de desmatamento em Otto bacias do bioma Cerrado obtidas através de imagens índice de vegetação Modis. In: XIV Simpósio Brasileiro de Sensoriamento Remoto. Natal-Brasil, 25 a 30 de Abril de 2009, INPE, p. 6241-6248.

ROCHA, G. F.; FERREIRA, L. G.; FERREIRA, N. C.; FERREIRA, M. E.; SILVA, G. N. F. Distribuição espacial dos dados de alertas de desmatamentos do bioma Cerrado para o período 2003-2007. In: XIV Simpósio Brasileiro de Sensoriamento Remoto. Natal-Brasil, 25 a 30 de Abril de 2009, INPE, p. 2983-2988.

Janete Rêgo Silva - Mestre em Geografia pela Universidade Federal de Goiás. Atualmente é professora pela Universidade Estadual de Goiás.

Nilson Clementino Ferreira - Doutor em Ciências Ambientais pela Universidade Federal de Goiás. Atualmente é professor da Universidade Federal de Goiás.

Recebido para publicação em novembro de 2010 Aceito para publicação em maio de 2011 